\title{
Is Atorvastatin Associated with New Onset Diabetes or Deterioration of Glycemic Control? Systematic Review Using Data from 1.9 Million Patients
}

\author{
Angeliki M. Angelidi ${ }^{D},{ }^{1}$ Emelina Stambolliu $\left(\mathbb{D},{ }^{1,2}\right.$ Konstantina I. Adamopoulou $\left(\mathbb{D}\right.$, ${ }^{1}$ \\ and Antonis A. Kousoulis $\mathbb{D D}^{1,3}$ \\ ${ }^{1}$ Society of Junior Doctors, Athens, Greece \\ ${ }^{2}$ Hypertension Center STRIDE-7, Third University Department of Medicine, Sotiria Hospital, Athens, Greece \\ ${ }^{3}$ Faculty of Epidemiology and Population Health, London School of Hygiene \& Tropical Medicine, London WC1E 7HT, UK
}

Correspondence should be addressed to Angeliki M. Angelidi; angieang9@gmail.com

Received 24 June 2018; Accepted 24 September 2018; Published 22 October 2018

Academic Editor: Matteo Monami

Copyright (c) 2018 Angeliki M. Angelidi et al. This is an open access article distributed under the Creative Commons Attribution License, which permits unrestricted use, distribution, and reproduction in any medium, provided the original work is properly cited.

\begin{abstract}
Background. Current evidence indicates that statins increase the risk of new onset diabetes mellitus (NOD) and also deteriorate the glycemic control in patients with known diabetes mellitus (DM) after high-dose statin therapy. Aims. The aim of this review was to explore the effect of atorvastatin in causing NOD or deteriorating glycemic control in patients with DM. Methods. Two independent reviewers conducted the literature search, through PubMed database searching for articles published in English until April 2015, and only primary studies were included. Results. Of the 919 articles identified in our original search, 33 met the criteria for this review encompassing 1,951,113 participants. Twenty articles examined dysregulation of DM due to atorvastatin. Half of them showed that there was no significant change in glycemic control in patients treated with atorvastatin. Other studies showed that fasting plasma glucose and HbAlc levels were increased by atorvastatin. Thirteen articles examined if atorvastatin causes NOD. The majority of these articles showed that patients who used atorvastatin had a higher dose-dependent risk of developing NOD. Conclusion. This systematic review suggests that there is an association between atorvastatin treatment and NOD. Moreover, it showed that atorvastatin in high dose causes worsening of the glycemic control in patients with DM.
\end{abstract}

\section{Introduction}

Dyslipidemia is a primary well-established independent risk factor for cardiovascular disease [1]. An effective treatment, the 3-hydroxy-3-methylglutaryl coenzyme A (HMG-CoA) reductase inhibitors (also known as statins) are proven to lower low-density lipoprotein (LDL) cholesterol levels in patients with hypercholesterolemia [2].

Multiple prospective studies have showed the cardioprotective and antioxidant effects of statins, which have widely and for many decades been used for that purpose $[3,4]$. LDL-cholesterol levels remain the principal target for lipid modification and statin therapy as the main treatment of achieving LDL goal attainment. The beneficial effect of statins in both primary and secondary prevention of cardiovascular events by lowering LDL-cholesterol concentrations has been documented among patients with or without diabetes $[5,6]$.

Diabetes mellitus is a growing public health problem that is approaching epidemic proportions globally, and it is also related with increased cardiovascular risk. In adults aged over 40 with diabetes mellitus, according to the American Diabetes Association (ADA) [7] and ACC/AHA guidelines [8], statin treatment is recommended, while it should also be considered for those less than 40 years old based on their risk profile.

Statin therapy is associated with significant reduction in cardiovascular endpoints; however, concerns have been raised over the use of statins and an increased risk of diabetes. Several statins are now available, with different potencies 
and drug interactions such as atorvastatin, pitavastatin, simvastatin, and rosuvastatin. However, their influence on insulin levels and insulin resistance has not been clarified yet. There are some theories suggesting a potential risk of developing new onset diabetes mellitus (NOD) [9] or a risk of deteriorating the glycemic control in patients with diabetes after high-dose statin therapy [10]. This risk is seemingly elevated with the use of atorvastatin [11]. Therefore, many clinical trials [12-14] have investigated the possible association between atorvastatin and new onset diabetes or dysregulation of already existing diabetes as well as the underlying mechanisms. It has also been reported that some groups with special characteristics, such as postmenopausal women [15] and renal allograft recipients [16], are in particular danger. On the other hand, few studies have demonstrated that atorvastatin did not worsen insulin sensitivity in patients with diabetes $[17,18]$, whereas one study suggested that patients treated with atorvastatin may be at a lower risk of developing new onset diabetes [14].

The aim of this review was to look systematically into the current literature and carefully collect and analyse results to explore the potential effect of atorvastatin in both causing new onset diabetes and deterioration of glycemic control in patients with known diabetes.

\section{Methods}

2.1. Literature Search. This review has adopted the Preferred Reporting Items for Systematic Reviews and Meta-Analyses (PRISMA) guidelines. A systematic search strategy was followed. PubMed database was used to search for publications of interest using as keywords "atorvastatin AND diabetes." Eligible studies were primary studies of every design (observational studies, cross-sectional, cohort, case studies, case series, clinical trials, etc.) published in English until 30/ 04/2015 (date of last search). Secondary studies (reviews, letters, and meta-analyses) as well as studies published in languages other than English were excluded. Two reviewers working independently conducted the literature search.

2.2. Data Collection and Synthesis. The titles of studies, which were considered for retrieval, were recorded on a form and then were classified on an inclusion and exclusion search diary. All the articles that came up but were irrelevant or were secondary research were excluded. Studies were selected for retrieval after two independent reviewers had collected titles and abstracts identified in electronic searches. The results of the two reviewers were compared by a third independent reviewer, and any differences of opinion were resolved by discussion. The corresponding authors were contacted on account of missing data. The included studies were grouped and presented in Summary Tables featuring key points of each study; the following data were collected: first author surname, study name, year of publication, study design, country, number of total population (percentage of male/ female), total population age (Mean-Standard DeviationMedian range), Quantitative results ( $\mathrm{HR}, p)$ of the study findings, diabetes status of the participants, and evidence of association between atorvastatin use and new onset diabetes mellitus or increased risk for worsening of glycemic control. Outcome measures of included studies were organized and then analysed cumulatively. Given the lack of primary data, a narrative form of synthesis was adopted as a way of expressing and synthesizing the results of the eligible studies (i.e., numerical data expressed as weighted means whenever possible). No further statistical analysis was possible.

\section{Results}

In total, 919 articles were identified through database searching, which were reduced to 642 articles after removing duplicates. In all, 33 articles were eligible for the review, following exclusions. Eighteen clinical trials $[1-3,5,9,10$, $13,17,19-28], 14$ cohort studies [11, 12, 14-16, 18, 29-36], and one case control study [37] involving a total of $1,951,113$ participants were included in the current review. A relevant flow chart was constructed to detail the number of papers retrieved and the steps undertaken (Figure 1).

It should be noted that the primary endpoints of the included studies were cardiovascular disease, LDLcholesterol levels, HDL-cholesterol levels, or other outcomes such as serum triglyceride levels, apolipoprotein B, serum dehydroepiandrosterone sulfate levels, and C-reactive protein levels. However, all the included studies reported evidence of glycemic control or the incidence of new onset diabetes as secondary endpoints. The proportion of females in the studies ranged between $0 \%$ and $100 \%$. More specifically, the total female population was $1,197,855-$ 1,197,955 (approximately 1,197,900) (61.4\%). Three studies had only females $[15,25,37]$ and 2 studies had only males $[28,34]$. In the majority of studies, females were almost as many as males.

The mean average age of the subjects by study (for which age data were available) ranged between 44 and 74.9 years. Thirteen studies included only patients with type 2 diabetes mellitus [2, 3, 10, 11, 17-19, 21, 27-30, 33], while 3 studies included only patients with type 1 diabetes mellitus $[13,20,24]$. The average time since diagnosis of diabetes ranged between 4 and 26 years. The participants had been followed for an average of 4 months to 5 years (weighted average, 3.6 years).

Of note, Koh et al. [9] compared the effect of atorvastatin at doses of $10 \mathrm{mg}, 20 \mathrm{mg}, 40 \mathrm{mg}$, and $80 \mathrm{mg}$. Fasting plasma insulin (mean changes: $25 \%, 42 \%, 31 \%$, and $45 \%$ ) and $\mathrm{HbAlc}$ levels $(2 \%, 5 \%, 5 \%$, and $5 \%)$ were increased by atorvastatin $10,20,40$, and $80 \mathrm{mg}$ when contrast with either baseline (all $p<0.05$ by paired $t$-test) or placebo $(p=0.009$ for insulin and $p=0.008$ for HbA1c by ANOVA). Atorvastatin 10, 20, 40 , and $80 \mathrm{mg}$ declined insulin sensitivity (1\%, 3\%, 3\%, and $4 \%$, respectively) when compared with either baseline $(p=0.312, p=0.008, p<0.001$, and $p=0.008$, respectively, by paired $t$-test) or placebo ( $p=0.033$ by ANOVA).

Baseline characteristics of the enrolled participants were generally similar between the groups in each study. Information regarding the included studies is presented in Tables 1 and 2 . 


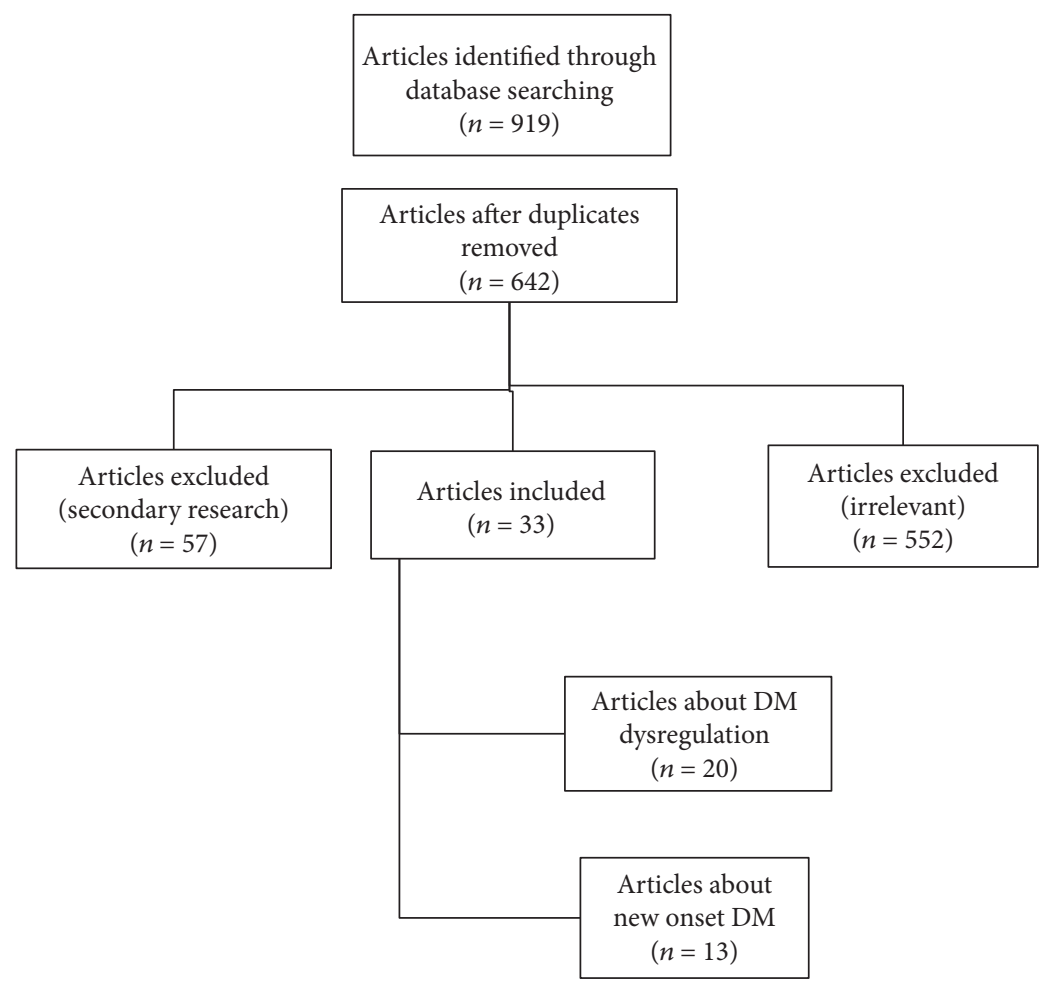

FIgURE 1: Flowchart of the systematic review process.

The mean baseline HbA1c across the studies (weighted average) was $7.2 \%(56 \mathrm{mmol} / \mathrm{mol})$ in the statin group and $7.3 \%(57 \mathrm{mmol} / \mathrm{mol})$ in the control group. At the end of the studies, the mean $\mathrm{HbAlc}$ was $7.4 \%$ (57 $\mathrm{mmol} / \mathrm{mol}$ ) in the statin group and $7.2 \%(55 \mathrm{mmol} / \mathrm{mol})$ in the control group. The mean baseline fasting glucose across the studies (weighted average) was $7.28 \mathrm{mmol} / \mathrm{L}$ in the atorvastatin group and $7.49 \mathrm{mmol} / \mathrm{L}$ in the control group. At the end of the studies, the mean fasting glucose was $7.84 \mathrm{mmol} / \mathrm{L}$ in the atorvastatin group and $7.20 \mathrm{mmol} / \mathrm{L}$ in the control group.

3.1. New Onset Diabetes Mellitus. Thirteen articles [1, 12, 14$16,22,26,31,32,34-37], 3$ of which were clinical trials, examined the association between atorvastatin use and NOD. Patients who used atorvastatin had a higher risk of developing NOD. Also, the results of the majority of studies indicated that the risk of diabetes was dose dependent for atorvastatin. The majority of the articles and all the clinical trials showed that high-dose, compared with lower-dose, atorvastatin increased the risk of NOD. Waters et al. [22] noted that in the TNT clinical trial the HR was 1.10 between those who took atorvastatin $10 \mathrm{mg}$ and $80 \mathrm{mg}$. Further, the absolute rates of new onset T2DM were $6.40 \%$ in the group who took atorvastatin and $6.06 \%$ in the placebo group according to the SPARCL clinical trial. The SPARCL clinical trial was a multicenter, double blind, parallel-group, randomized, placebo-controlled trial which randomized patients with prior stroke or transient ischemic attack (TIA) but without known heart disease [38].
However, in one study, the low dose of atorvastatin was related to a small increased risk of NOD (OR: 1.99, 95\% CI: $1.00-3.98, p$ value 0.050 ) [36].

Moreover, statin medication use in postmenopausal women was shown to be associated with an increased risk for DM [15].

3.2. Dysregulation of Glycemic Control. Twenty articles examined if deterioration of diabetes mellitus is associated with the use of atorvastatin $[2,3,5,9-11,13,17-21,23-$ $25,27-30,33], 15$ of which were clinical trials. Worsening of glycemic control was examined by measuring parameters related to glucose level such as fasting plasma glucose and $\mathrm{HbA} 1 \mathrm{c}$.

Ten studies showed that there was no significant change in glycemic control in patients treated with atorvastatin $[2,3,17-19,24,27-30]$.

On the other hand, in 8 studies, atorvastatin use tended to be an independent predictor of increasing $\mathrm{HbAlc}$ levels and/or fasting plasma glucose levels $(p<0.001)$ [9-11, 13, $20,21,23,33]$.

In addition, it was noticed that fasting plasma glucose and $\mathrm{HbAlc}$ increased in the group that received higher doses of atorvastatin [5].

The rates of new onset T2DM were higher in groups that took higher dose of atorvastatin. The absolute rates of new onset T2DM were $9.24 \%$ in the group who took $80 \mathrm{mg}$ atorvastatin and $8.11 \%$ in the group who took $10 \mathrm{mg}$ atorvastatin according to the TNT clinical trial [22]. Among clinical trials, the majority of studies indicated that 


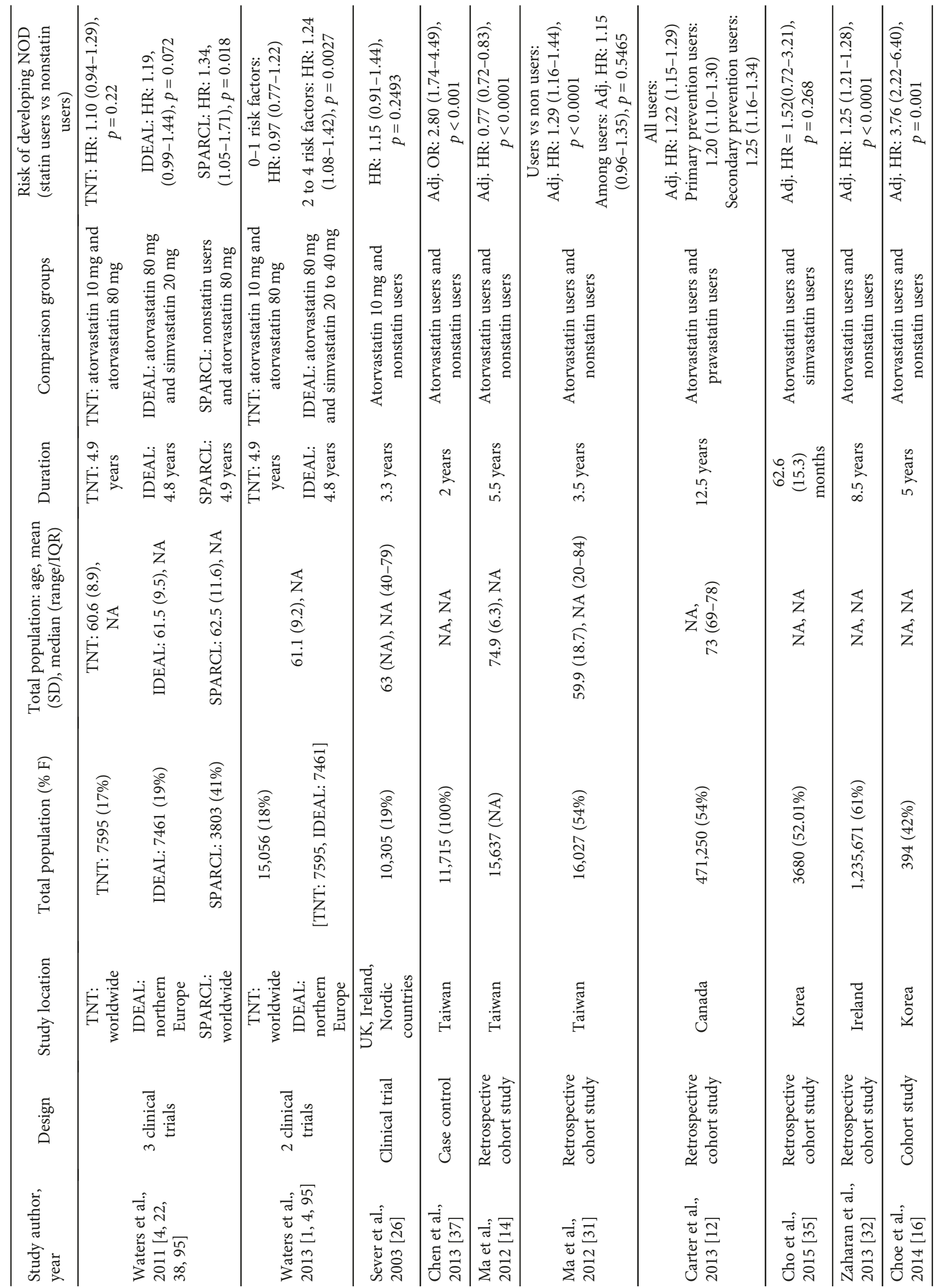




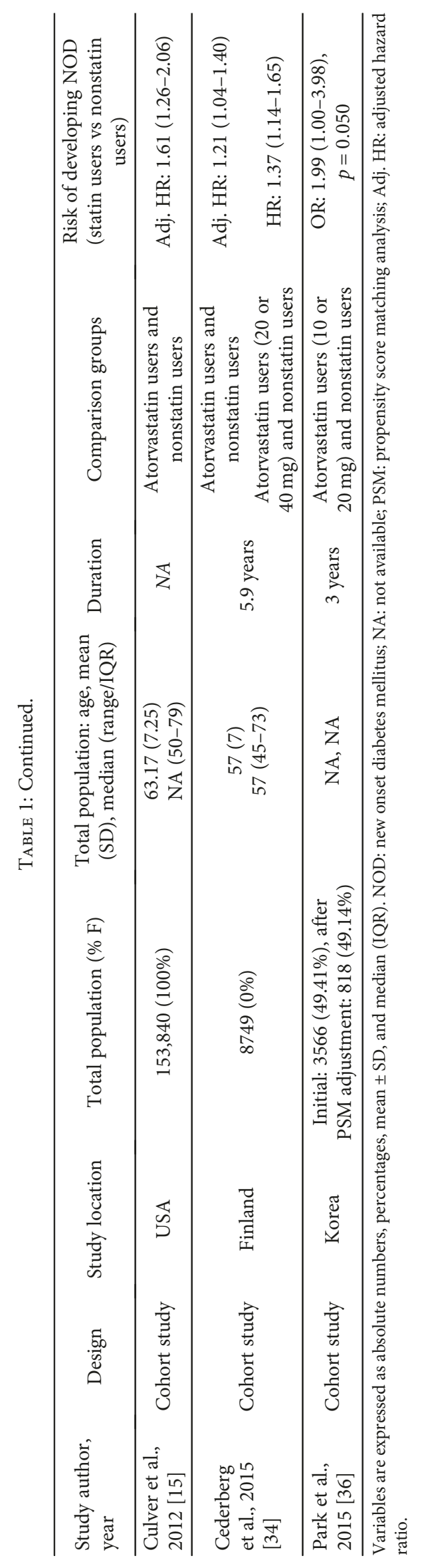




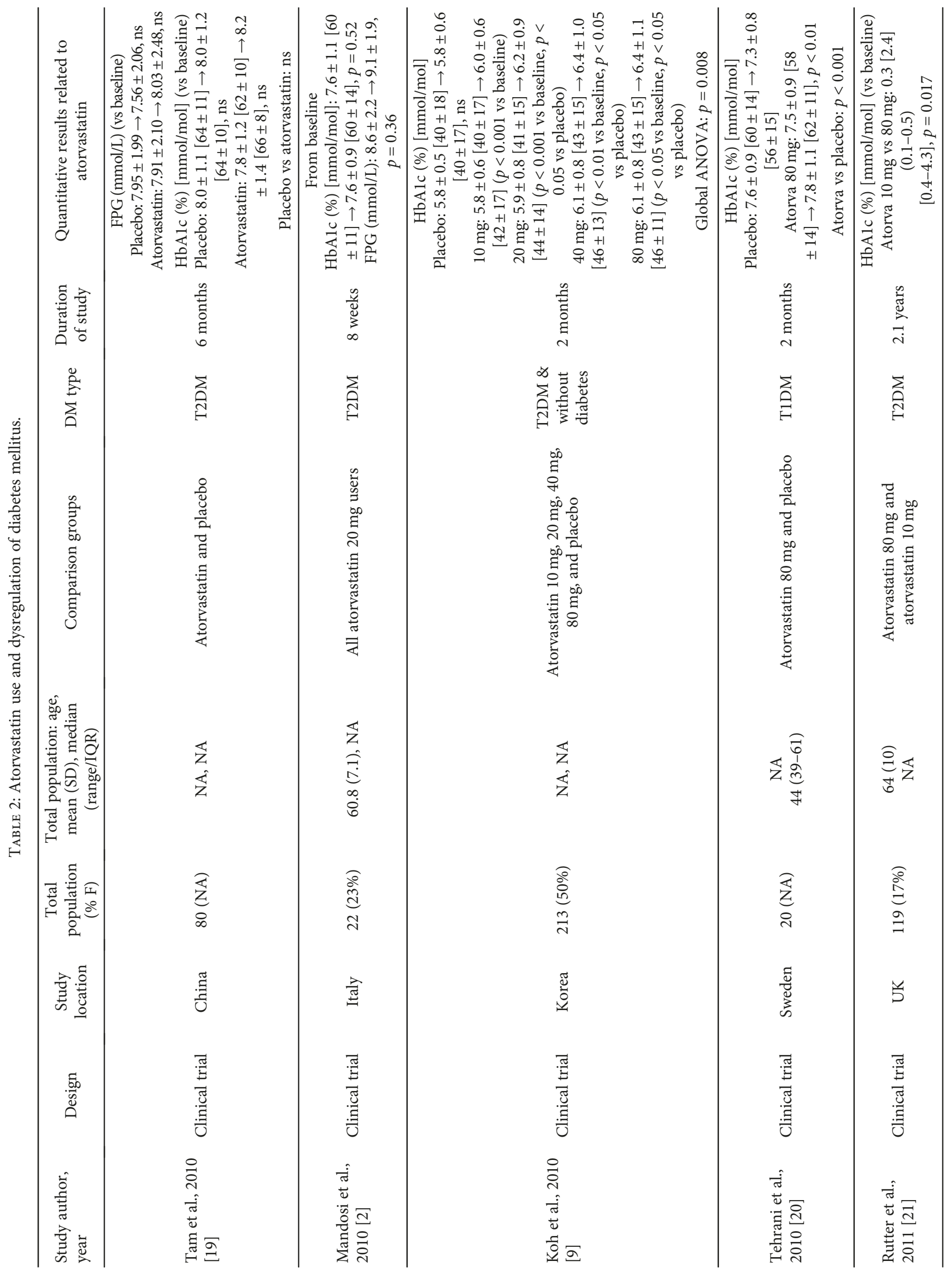




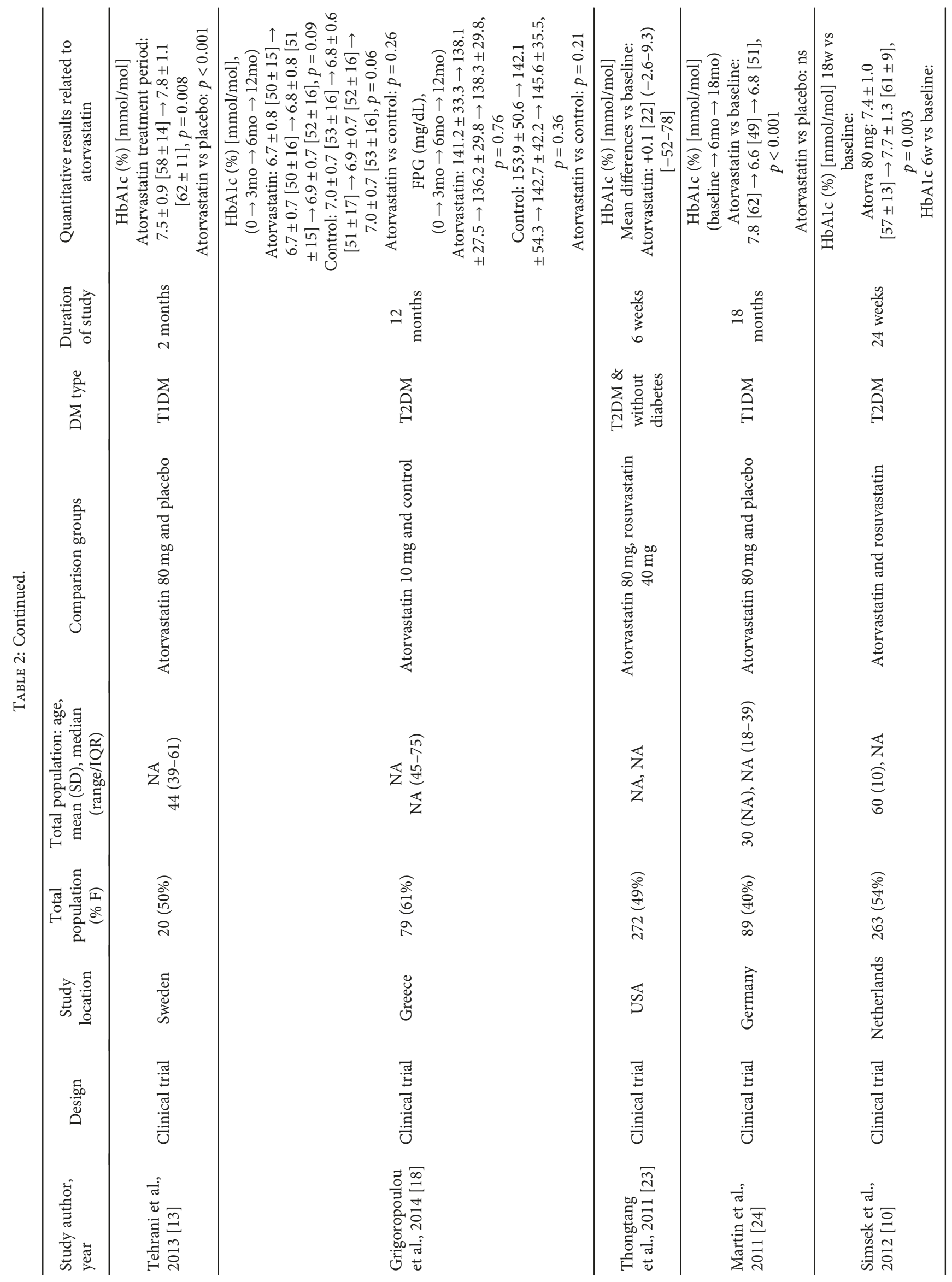




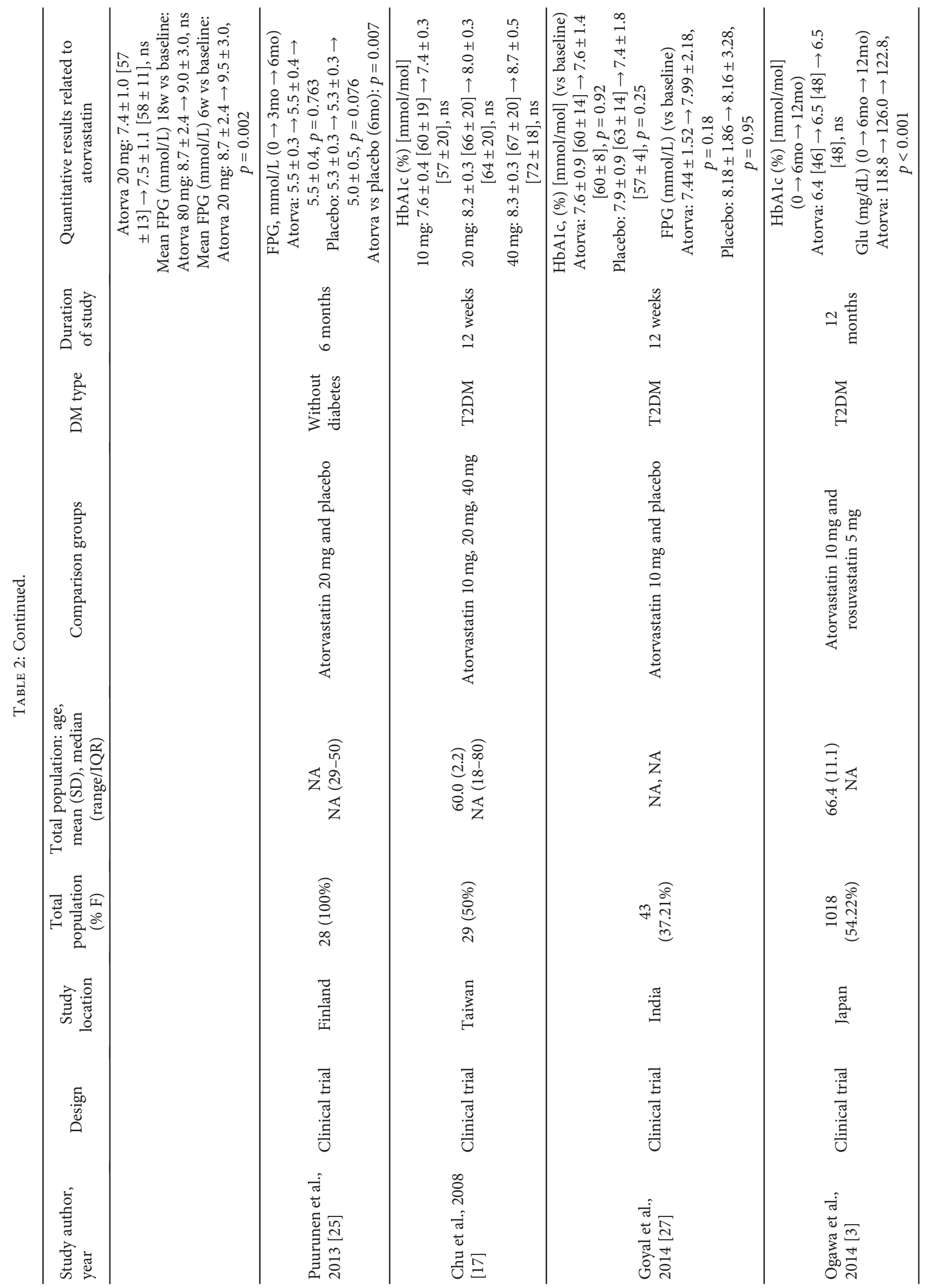




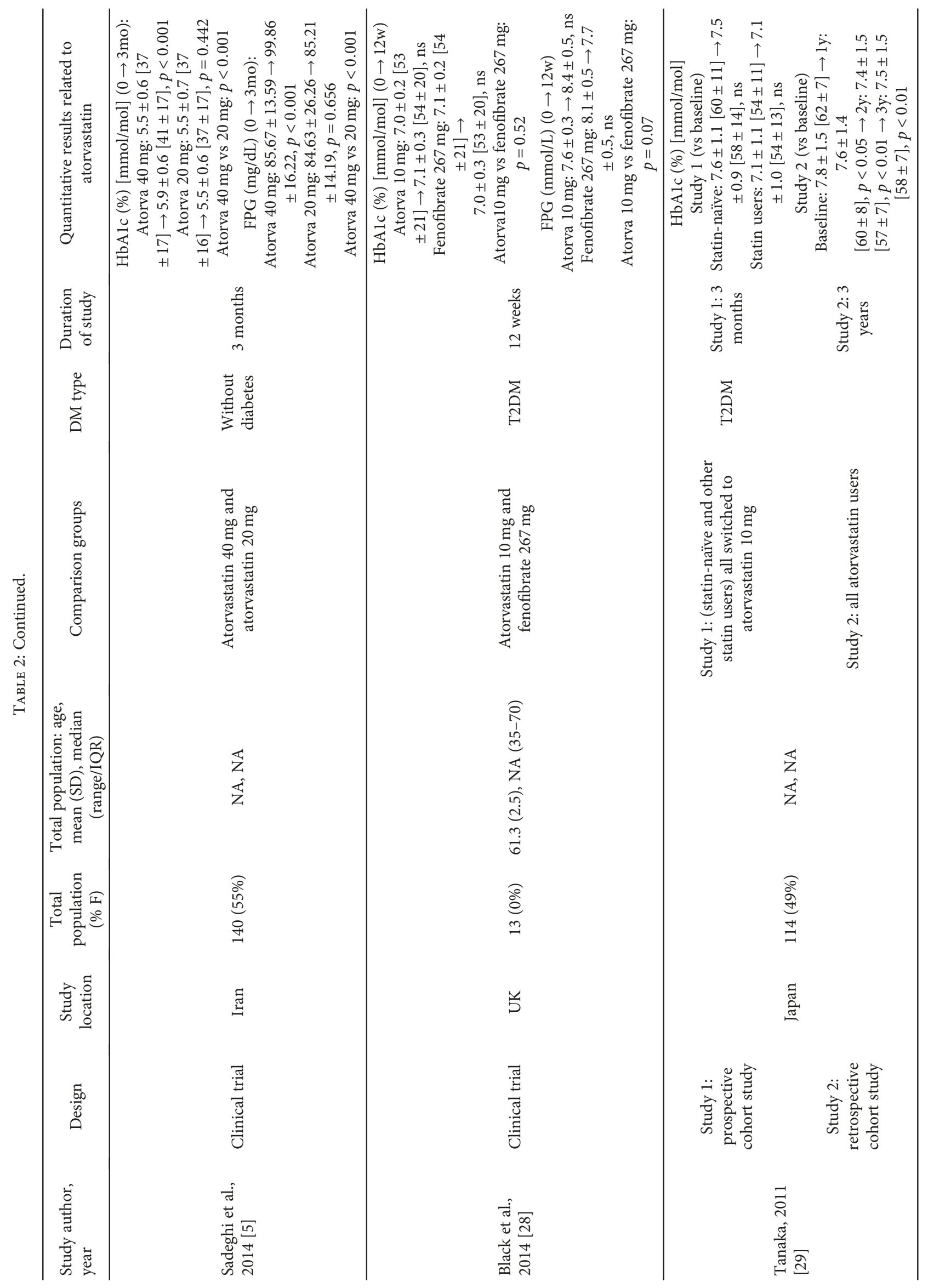




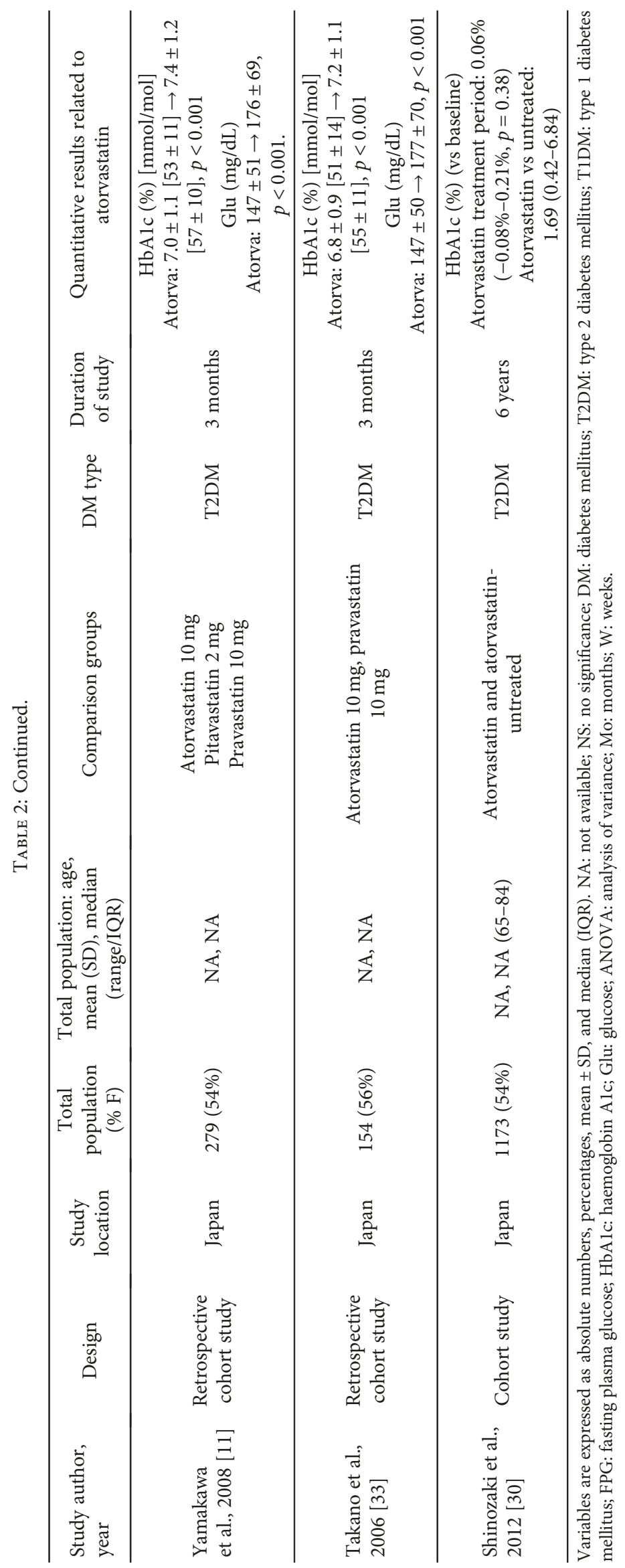


deregulation of diabetes mellitus (expressed mostly with increased HbA1c levels) was more frequent in the statin group than in the placebo group.

\section{Discussion}

Evidence from randomized clinical trials suggests that the benefits from preventing cardiovascular disease and mortality with statins overweigh the risk of new onset diabetes mellitus [39]. Nevertheless, in patients at low risk for cardiovascular implications, lipid-lowering therapy with statins should be carefully used, and lifestyle changes along with close blood glucose levels monitoring should constitute the first line of treatment [40]. Therefore, it is absolutely necessary for clinical doctors to evaluate the positive and the potential negative effects of statin therapy, taking into consideration the unique characteristics of each patient.

However, according to several studies, the risk of developing NOD varies with different types of statins. Patients who are treated with pravastatin and pitavastatin are in lower risk for adverse effects [41] than those treated with lipophilic statins, such as atorvastatin [11]. Furthermore, the dose of atorvastatin plays an important role. Higher dosage and more intensive treatment are associated with greater incidence of NOD [42]. It should also be noted that older patients, with impaired fasting glucose prior to the use of statins and with other characteristics of the metabolic syndrome, face a greater risk for diabetogenicity [43].

Not many systematic reviews or meta-analyses investigating the association of atorvastatin with NOD and glycemic control dysregulation have been published recently. More specifically, the latest review [44] examining this association, published in 2017, referred only to the correlation between different statins and new onset diabetes mellitus and did not provide detailed data concerning atorvastatin. Also, four previous meta-analyses [45-48] and one review [49] included data concerning all different statins and NOD, but there were no data about statins deteriorating the glycemic control in patients with preexisting diabetes. One meta-analysis [50] and one review [51] underlined only the detrimental effect of atorvastatin, among other statins, on the glycemic control in diabetic patients, unlike our review which is mainly concentrated on the effect of atorvastatin specifically on both NOD and deterioration of the glycemic control.

4.1. New Onset Diabetes Mellitus. In this review, we found that there is an association between atorvastatin use and new onset diabetes (NOD). The diabetogenic effect is more significant with high dose of atorvastatin $[1,32,34,37]$, although new data from a most recent cohort study suggest that low-dose atorvastatin $(10-20 \mathrm{mg})$ consists a risk factor for NOD [36], though results were based on a relatively small number of participants $(N=818)$. A recent study investigated whether there is association between statin use and new onset diabetes in postmenopausal women who took part in the Women's Health Initiative. It was revealed that all statins increase the risk of type 2 diabetes mellitus. Particularly, atorvastatin was associated with $61 \%$ increased risk of diabetes [15]. One cohort study demonstrated that, in comparison with pravastatin, patients treated with atorvastatin faced a $22 \%$ increase in the risk of new onset diabetes [12]. Another analysis, which collated data from 3 different clinical trials (TNT, SPARCL, and IDEAL) on atorvastatin, suggested that atorvastatin at the maximum dose $(80 \mathrm{mg})$ increased the risk for new onset diabetes by $34 \%$, and this was more obvious in the SPARCL trial [22]. Later results from the same clinical trials indicated that the risk for new onset diabetes for patients with 2-4 risk factors was elevated by $24 \%$ with high-dose atorvastatin, while there was no diabetogenic effect on patients with $0-1$ risk factor [1]. It should also be mentioned that atorvastatin treatment caused dysglycemia (impaired fasting glucose and diabetes mellitus) in a high percentage of renal allograft recipients as indicated by a recent cohort study [16]. However, a retrospective cohort study has shown that atorvastatin had a neutral effect on new onset diabetes, which is dose-response [31], and another study reported that not only does atorvastatin not elevate the risk of diabetes but also may have a protective effect for elderly hypertensive and dyslipidaemic patients [14]. A potential explanation for this may be that the participants had median age of 74.9 years, and there is no record of the dosage of atorvastatin used during the study. No association between atorvastatin and new onset diabetes was demonstrated by one study [26], but this may be attributed to the fact that the lowest dose of atorvastatin $(10 \mathrm{mg})$ was used for this study.

4.2. Dysregulation of Glycemic Control. As far as glycemic control is concerned, this review has shown that high dose of atorvastatin is associated with the deterioration and worsening of glucose homeostasis [13, 21, 23, 33]. A clinical trial published in 2010 reported that atorvastatin $10 \mathrm{mg}$ compared to atorvastatin $80 \mathrm{mg}$ increased fasting plasma glucose (FPG) by $25 \%$ and $45 \%$, respectively, and HbA1c by $2 \%$ and $5 \%$, respectively [9]. The influence of high-dose atorvastatin on glycemic control was also demonstrated by 2 different studies, which reported a significant increase $(0.3 \%)$ of HbAlc compared to baseline along with no alteration in FPG levels [10, 20].

No significant changes in glycemic control between the atorvastatin group and the control group were found by a clinical trial in China [19], but this was a lowquality study (follow-up of 6 months in population of 80 patients and the exact dose of atorvastatin used was not reported). Furthermore, a mediocre increase $(0.06 \%)$ of HbAlc was documented for patients treated with atorvastatin compared to the control group according to a recent study; however, no data regarding the dosage of atorvastatin were available [30]. Another study that has also shown no difference in the glycemic control is a clinical trial from Greece, which included only 79 participants who were treated with a low dose $(10 \mathrm{mg})$ of atorvastatin [18]. A neutral effect of atorvastatin $10 \mathrm{mg}$ was also reported by 3 more studies [3, 27, 28]. Finally, 2 clinical studies which used atorvastatin $20 \mathrm{mg}[2,25]$ and one with atorvastatin groups of 10-20-40 mg, respectively [17, 25], showed no association. 
A positive effect on $\mathrm{HbAlc}$ levels was suggested by one study investigating the effects of atorvastatin in renal function of patients with diabetes [29]. This retrospective cohort study showed that $\mathrm{HbAlc}$ was significantly decreased at 1 , 2 , and 3 years. There was no information about the dosage of atorvastatin. In a different trial, a nonsignificant decrease of $\mathrm{HbA1c}$ was reported in patients treated with atorvastatin high dose (80 mg) compared to placebo [24].

4.3. Mechanisms. Lipid-lowering drugs intervene with glucose control and insulin sensitivity in many different ways. Mainly, HbA1c and FPG are affected. Although the precise underlying pathogenetic mechanisms that lead to the development of diabetes are not yet scientifically proven, there are some studies which suggest that the intervention of statins in the Mevalonate path and hence in the isoprenoids' synthesis is connected with the deterioration of glycemic control [9]. Statin treatment also results in the downregulation of glucose transporter 4 (GLUT4) in adipocytes, which causes insulin resistance [52]. Furthermore, statins decrease insulin secretion via the decrease of glucose-dependent intracellular calcium concentration [53] and via the inhibition of ubiquinone (CoQ10), which leads to reduction of ATP in pancreatic $\beta$-cells [54]. These effects are more intense with lipophilic statins like atorvastatin than with hydrophilic statins like pravastatin [55]. Other plausible mechanisms, including genetic factors, have also been explored but with no concrete evidence yet.

4.4. Drugs That May Have a Metabolic Effect on Insulin Resistance and on the Development of Diabetes. Several classes of antidiabetic drugs are available. Each category has a distinct pathophysiological mechanism of action and consequently a different effect regarding insulin resistance and $\beta$-cell pancreatic function.

Indicatively, metformin inhibits hepatic gluconeogenesis and also improves insulin sensitivity via activation of AMPactivated protein kinase (AMPK) signalling and reducing cAMP (cyclic adenosine monophosphate) levels. Moreover, metformin is associated with microbiome modification of the gastrointestinal tract and entails an increase of incretin (glucagon-like peptide-1, GLP-1) secretion and glucose utilization [56].

Pioglitazone binds and activates the peroxisome proliferator-activated receptor (PPAR) $\gamma$ leading to metabolic changes concerning carbohydrate and lipid metabolism. It is associated with an increase in tissue sensitivity to insulin and subsequently an enhanced glucose uptake in the skeletal muscle and adipose tissue. Also, it causes a reduction in hepatic glucose production and an increase in hepatic glucose uptake. It may stimulate $\beta$-cell insulin production and may have beneficial effects both on endothelial and pancreatic $\beta$-cells [57-59].

Sulfonylureas stimulate the endogenous secretion of insulin from pancreatic $\beta$-cells by inhibiting the ATPsensitive K-channels. Therefore, sulfonylureas exert their effects only when residual $\beta$-cells exist $[60,61]$.

Reduced incretin levels may play a part in the pathogenesis of T2DM. Incretin-based therapies, dipeptidyl peptidase-
4 (DPP-4) inhibitors, and GLP-1 receptor agonists (GLP1RAs) affect glucose control via pleiotropic mechanisms and play a significant role in glucose homeostasis.

GLP-1RAs enhance glucose-dependent insulin secretion, delay gastric emptying, and reduce food intake and postprandial glucagon secretion [62].

DPP4 inhibitors delay the inactivation of incretin hormones, also resulting in increased insulin synthesis and decreased glucagon levels in a glucose-dependent manner [63].

According to clinical and preclinical study results, incretin-based therapies may have a beneficial effect on hepatic steatosis and steatohepatitis, inhibit intestinal lipoprotein production, enhance $\beta$-cell function, and produce multiple biological actions in peripheral tissues $[63,64]$.

On the other hand, various nondiabetic drugs seem to play a crucial role in insulin sensitivity and endothelial dysfunction [65]. Several experimental evidence suggests that overactivity of renin-angiotensin-aldosterone system (RAAS), namely angiotensin II, interferes with insulin resistance and glucose metabolism [66]. Thus, drugs with RAAS blockade activity may interact with the skeletal muscle, adipose tissue, or pancreas contributing to altered glucose metabolism and insulin sensitivity.

It has been shown that angiotensin II interferes with insulin metabolic signalling, induces insulin resistance, and impairs insulin-stimulated glucose disposal. It inhibits insulin receptor substrates 1 and 2 (IRS-1, IRS-2), enhances serine phosphorylation affecting the PI3K (phosphoinositide 3-kinase) pathway, impairs the insulin-mediated vasodilation, and also reduces the ability of IRS- 1 to interact with the activated insulin receptor $[67,68]$.

It has also been proposed that angiotensin II is associated with the functional impairment of pancreatic $\beta$-cells through inflammation, attenuation of islet fibrosis, and oxidative damage of the pancreas. The metabolic stress, as well as the dedifferentiated status of $\beta$-cells induced by angiotensin II, has also been associated with pancreatic $\beta$-cell failure and the potential progressive development of T2DM [69-71].

Angiotensin II receptor blockers (ARBs) are drugs that block the action of angiotensin II by selectively inhibiting its binding to angiotensin II receptors on the muscles surrounding blood vessels.

According to some studies, ARB medications improved insulin sensitivity [72-74] while others showed an enhancement in the early phase of insulin secretion, a significant effect possibly attributed to the recovery of pancreatic $\beta$-cell function $[75,76]$.

ACE (angiotensin-converting-enzyme) inhibitors are also involved in the renin-angiotensin axis. It has been proposed that ACE inhibitors promote glycemia and glucose tolerance probably though preservation of $\beta$-cell function [77], improvement of insulin sensitivity (via activation of bradykinin-nitric oxide pathway) [78], antiinflammatory processes [79], and multiple other underlying mechanisms $[80,81]$.

It is evident that apart from their antihypertensive effect, both ARBs and ACE inhibitors may exert beneficial 
effects on lipid and carbohydrate metabolism and insulin resistance $[66,82,83]$, which may explain the possible protective role of these medications partially [84-86]. Furthermore, existing evidence demonstrates a potential protective role of RAAS inhibitors in new onset of T2DM [86-88].

Fibrates are a class of hypolipidemic agents that exert their effects through activation of PPARs, namely $\operatorname{PPAR} \alpha$, which modulate carbohydrate and lipid metabolism and adipose tissue differentiation. According to several studies, including patients with T2DM, fibrates and especially fenofibrate improved lipidemic parameters, insulin resistance, and glycemic control [89-91]. Moreover, a further investigation is proposed to examine the potential protective role of fibrates in preventing T2DM [92].

Additionally, other lipid-lowering drugs such as ANGPTL3 antisense oligonucleotides are also associated with an improvement of insulin sensitivity [93].

Taking into account all the aforementioned, it seems essential to clarify the underlying pathophysiologic mechanisms of action for each drug, their impact on insulin resistance and on the overall glucose homeostasis especially in patients with T2DM or in patients at high risk of NOD who also receive statin therapy [65].

4.5. Strengths and Limitations. This systematic review includes approximately 2,000,000 participants in total from all studies, contributing to a large cohort. In addition, a comprehensive literature search was followed, as well as bias protection methods such as three independent reviewers.

Of note, our data were extracted from more recent clinical studies, the latest of which conducted in 2015, in contrast to aforementioned review studies. Two reviews [41, 94], with clinical trials until 2009 and 2013, respectively, found no association between atorvastatin and NOD as well as atorvastatin and deterioration of the glycemic control. The review by Kostapanos et al. [94] included a very small number of subjects and mainly low doses of atorvastatin, while the review by Naci et al. [41] investigated only the incidence of NOD in trials that were not designed for this purpose and had no information about the doses of atorvastatin used.

However, the limitations of the review should be acknowledged. Firstly, the medical status of each participant (e.g., coexisting diseases) and the concomitant medications (especially the glucose-lowering agents or other drugs with metabolic impact, as already mentioned) were not taken into account, since data were not consistently available. Furthermore, only clinical studies published in PubMed were included, thus results from nonindexed trials are missing. All studies not published in the English language were excluded. Further, about a third (13 of 33) of the included studies used observational designs. Finally, most of the studies were not designed to investigate the association between atorvastatin and new onset diabetes or dysregulation of existing diabetes mellitus, but their primary designation purpose was different, contributing to the heterogeneity of the results.

\section{Conclusions}

Our findings suggest that there is association between atorvastatin treatment and new onset diabetes mellitus. It was also demonstrated that atorvastatin causes worsening of glycemic control in patients with known diabetes but only in maximum dose and not in lower doses. Nevertheless, serious consideration needs to be placed on the cost-benefit ratio and the potential importance of these adverse effects of atorvastatin when compared to the scientifically and clinically observed beneficial effects of statins on cardiovascular risk. Given the wide availability of statins and relevant databases, more studies using routine clinical data are required to be conducted, on wider homogeneous populations of participants and with larger periods of follow-up, in order to clarify the real association between statin therapy and the development of new onset diabetes mellitus. Moreover, the impact of other coadministrated drugs on insulin resistance and glucose homeostasis should be taken into deep consideration.

Hence, our review underlines the existence of a significant yet not so thoroughly investigated issue, which is the development of NOD and also the potential deterioration of the glycemic control by atorvastatin in patients with diabetes.

\section{Abbreviations}

NOD: $\quad$ New onset diabetes mellitus

HMG-CoA: 3-Hydroxy-3-methylglutaryl coenzyme A

LDL: $\quad$ Low-density lipoprotein cholesterol

HDL: High-density lipoprotein cholesterol

HR: $\quad$ Hazard ratio

SD: $\quad$ Standard deviation

IQR: Interquartile range

OR: $\quad$ Odds ratio

NA: Not available

NS: $\quad$ No significance

DM: $\quad$ Diabetes mellitus

T2DM: $\quad$ Type 2 diabetes mellitus

T1DM: $\quad$ Type 1 diabetes mellitus

FPG: $\quad$ Fasting plasma glucose

HbA1c: Haemoglobin A1c

Glu: $\quad$ Glucose

ANOVA: Analysis of variance

Y: $\quad$ Years

Mo: $\quad$ Months

W: Weeks

PSM: $\quad$ Propensity score matching analysis

ATORVA: Atorvastatin

ADA: American Diabetes Association

PRISMA: Preferred reporting items for systematic reviews and meta-analyses

ACC/AHA: American College of Cardiology and the American Heart Association

AMPK: $\quad$ AMP-activated protein kinase

cAMP: $\quad$ Cyclic adenosine monophosphate

GLP-1: $\quad$ Glucagon-like peptide-1

GLP-1RAs: GLP-1 receptor agonists 
DPP-4: Dipeptidyl peptidase-4

RAAS: Renin-angiotensin-aldosterone system

IRS-1: Insulin receptor substrates 1

IRS-2: Insulin receptor substrates 2

ARBs: $\quad$ Angiotensin II receptor blockers

ACE: Angiotensin-converting-enzyme

PPARs: Peroxisome proliferator-activated receptors.

\section{Additional Points}

Key points. Atorvastatin may cause dysregulation of glycemic control in patients with diabetes. Association between atorvastatin treatment and new onset diabetes mellitus. Deterioration of glycemic control is increased after high-dose atorvastatin therapy. Association of new onset diabetes mellitus with high-dose atorvastatin therapy. More studies are required to clarify the underlying mechanisms and the real association between statin therapy and the development of new onset diabetes mellitus.

\section{Conflicts of Interest}

The authors declare that they have no conflicts of interest concerning this article.

\section{Authors' Contributions}

$\mathrm{AA}$ and $\mathrm{AK}$ contributed to the conception of the study and designed the study. AA, ES, and KA were involved in the literature research and collection and assembly of the data. $\mathrm{AA}$ and $\mathrm{AK}$ led on reaching consensus on study inclusion and data extraction. ES, KA, and AA wrote the manuscript. $\mathrm{AK}$ and $\mathrm{AA}$ participated in editing and revising the manuscript. All authors read and approved the final manuscript.

\section{References}

[1] D. D. Waters, J. E. Ho, S. M. Boekholdt et al., "Cardiovascular event reduction versus new-onset diabetes during atorvastatin therapy: effect of baseline risk factors for diabetes," Journal of the American College of Cardiology, vol. 61, no. 2, pp. 148152, 2013.

[2] E. Mandosi, M. Fallarino, A. Gatti et al., "Atorvastatin downregulates monocyte CD36 expression, nuclear NFkappaB and TNFalpha levels in type 2 diabetes," Journal of Atherosclerosis and Thrombosis, vol. 17, no. 6, pp. 539-545, 2010.

[3] H. Ogawa, K. Matsui, Y. Saito et al., "Differences between rosuvastatin and atorvastatin in lipid-lowering action and effect on glucose metabolism in Japanese hypercholesterolemic patients with concurrent diabetes. Lipid-lowering with highly potent statins in hyperlipidemia with type 2 diabetes patients (LISTEN) study," Circulation Journal, vol. 78, no. 10, pp. 2512-2515, 2014.

[4] J. C. LaRosa, S. M. Grundy, D. D. Waters et al., "Intensive lipid lowering with atorvastatin in patients with stable coronary disease," The New England Journal of Medicine, vol. 352, no. 14, pp. 1425-1435, 2005.

[5] R. Sadeghi, M. Asadpour-Piranfar, M. Asadollahi, M. Taherkhani, and F. Baseri, "The effects of different doses of atorvastatin on serum lipid profile, glycemic control, and liver enzymes in patients with ischemic cerebrovascular accident," ARYA Atherosclerosis, vol. 10, no. 6, pp. 298-304, 2014.

[6] M. Arca, "Atorvastatin efficacy in the prevention of cardiovascular events in patients with diabetes mellitus and/or metabolic syndrome," Drugs, vol. 67, Supplement 1, pp. 43-54, 2007.

[7] American Diabetes Association, "8. Cardiovascular disease and risk management," Diabetes Care, vol. 38, Supplement 1, pp. S49-S57, 2016.

[8] N. J. Stone, J. G. Robinson, A. H. Lichtenstein et al., "2013 ACC/AHA guideline on the treatment of blood cholesterol to reduce atherosclerotic cardiovascular risk in adults: a report of the American College of Cardiology/American Heart Association Task Force on Practice Guidelines," Circulation, vol. 129, no. 25, Supplement 2, pp. S1-S45, 2014.

[9] K. K. Koh, M. J. Quon, S. H. Han, Y. Lee, S. J. Kim, and E. K. Shin, "Atorvastatin causes insulin resistance and increases ambient glycemia in hypercholesterolemic patients," Journal of the American College of Cardiology, vol. 55, no. 12, pp. 1209-1216, 2010.

[10] S. Simsek, B. H. Wolffenbuttel, and C. G. Schalkwijk, "Effects of rosuvastatin and atorvastatin on glycaemic control in type 2 diabetes-the CORALL study," Diabetic Medicine, vol. 29, no. 5, pp. 628-631, 2012.

[11] T. Yamakawa, T. Takano, S. Tanaka, K. Kadonosono, and Y. Terauchi, "Influence of pitavastatin on glucose tolerance in patients with type 2 diabetes mellitus," Journal of Atherosclerosis and Thrombosis, vol. 15, no. 5, pp. 269-275, 2008.

[12] A. A. Carter, T. Gomes, X. Camacho, D. N. Juurlink, B. R. Shah, and M. M. Mamdani, "Risk of incident diabetes among patients treated with statins: population based study," BMJ, vol. 346, article f2610, 2013.

[13] S. Tehrani, F. Mobarrez, P. E. Lins, U. Adamson, H. N. Wallén, and G. Jörneskog, "Impaired endothelium-dependent skin microvascular function during high-dose atorvastatin treatment in patients with type 1 diabetes," Diabetes \& Vascular Disease Research, vol. 10, no. 6, pp. 483-488, 2013.

[14] T. Ma, M. H. Chang, L. Tien, Y. S. Liou, and G. P. Jong, "The long-term effect of statins on the risk of new-onset diabetes mellitus in elderly Taiwanese patients with hypertension and dyslipidaemia: a retrospective longitudinal cohort study," Drugs \& Aging, vol. 29, no. 1, pp. 45-51, 2012.

[15] A. L. Culver, I. S. Ockene, R. Balasubramanian et al., "Statin use and risk of diabetes mellitus in postmenopausal women in the Women's Health Initiative," Archives of Internal Medicine, vol. 172, no. 2, pp. 144-152, 2012.

[16] E. Y. Choe, H. J. Wang, O. Kwon et al., "HMG CoA reductase inhibitor treatment induces dysglycemia in renal allograft recipients," Transplantation, vol. 97, no. 4, pp. 419-425, 2014.

[17] C. H. Chu, J. K. Lee, H. C. Lam et al., “Atorvastatin does not affect insulin sensitivity and the adiponectin or leptin levels in hyperlipidemic type 2 diabetes," Journal of Endocrinological Investigation, vol. 31, no. 1, pp. 42-47, 2008.

[18] P. Grigoropoulou, I. Eleftheriadou, C. Zoupas et al., "Effect of atorvastatin on baroreflex sensitivity in subjects with type 2 diabetes and dyslipidaemia," Diabetes \& Vascular Disease Research, vol. 11, no. 1, pp. 26-33, 2013.

[19] H. L. Tam, S. W. M. Shiu, Y. Wong, W. S. Chow, D. J. Betteridge, and K. C. B. Tan, "Effects of atorvastatin on serum soluble receptors for advanced glycation end-products in type 2 diabetes," Atherosclerosis, vol. 209, no. 1, pp. 173-177, 2010. 
[20] S. Tehrani, F. Mobarrez, A. Antovic et al., "Atorvastatin has antithrombotic effects in patients with type 1 diabetes and dyslipidemia," Thrombosis Research, vol. 126, no. 3, pp. e225-e231, 2010.

[21] M. K. Rutter, H. R. Prais, V. Charlton-Menys et al., "Protection Against Nephropathy in Diabetes with Atorvastatin (PANDA): a randomized double-blind placebo-controlled trial of high- vs. low-dose atorvastatin(1)," Diabetic Medicine, vol. 28, no. 1, pp. 100-108, 2011.

[22] D. D. Waters, J. E. Ho, D. A. DeMicco et al., "Predictors of new-onset diabetes in patients treated with atorvastatin: results from 3 large randomized clinical trials," Journal of the American College of Cardiology, vol. 57, no. 14, pp. 1535-1545, 2011.

[23] N. Thongtang, M. Ai, S. Otokozawa et al., "Effects of maximal atorvastatin and rosuvastatin treatment on markers of glucose homeostasis and inflammation," The American Journal of Cardiology, vol. 107, no. 3, pp. 387-392, 2011.

[24] S. Martin, C. Herder, N. C. Schloot et al., "Residual beta cell function in newly diagnosed type 1 diabetes after treatment with atorvastatin: the randomized DIATOR trial," PLoS One, vol. 6, no. 3, article e17554, 2011.

[25] J. Puurunen, T. Piltonen, K. Puukka et al., "Statin therapy worsens insulin sensitivity in women with polycystic ovary syndrome (PCOS): a prospective, randomized, double-blind, placebo-controlled study," The Journal of Clinical Endocrinology and Metabolism, vol. 98, no. 12, pp. 4798-4807, 2013.

[26] P. S. Sever, B. Dahlöf, N. R. Poulter et al., "Prevention of coronary and stroke events with atorvastatin in hypertensive patients who have average or lower-than-average cholesterol concentrations, in the Anglo-Scandinavian Cardiac Outcomes Trial-Lipid Lowering Arm (ASCOT-LLA): a multicentre randomised controlled trial," Lancet, vol. 361, no. 9364, pp. 11491158, 2003.

[27] A. Goyal, S. Singh, N. Tandon, N. Gupta, and Y. K. Gupta, "Effect of atorvastatin on pancreatic beta-cell function and insulin resistance in type 2 diabetes mellitus patients: a randomized pilot study," Canadian Journal of Diabetes, vol. 38, no. 6, pp. 466-472, 2014.

[28] R. N. A. Black, C. N. Ennis, I. S. Young, S. J. Hunter, A. B. Atkinson, and P. M. Bell, "The peroxisome proliferatoractivated receptor alpha agonist fenofibrate has no effect on insulin sensitivity compared to atorvastatin in type 2 diabetes mellitus; a randomised, double-blind controlled trial," Journal of Diabetes and its Complications, vol. 28, no. 3, pp. 323-327, 2014.

[29] M. Tanaka, "Beneficial effect of atorvastatin on renal function in patients with type 2 diabetes," The Journal of International Medical Research, vol. 39, no. 4, pp. 1504-1512, 2011.

[30] T. Shinozaki, Y. Matsuyama, S. Iimuro et al., "Effective prevention of cardiovascular disease and diabetes-related events with atorvastatin in Japanese elderly patients with type 2 diabetes mellitus: adjusting for treatment changes using a marginal structural proportional hazards model and a rank-preserving structural failure time model," Geriatrics \& Gerontology International, vol. 12, pp. 88-102, 2012.

[31] T. Ma, L. Tien, C. L. Fang, Y. S. Liou, and G. P. Jong, "Statins and new-onset diabetes: a retrospective longitudinal cohort study," Clinical Therapeutics, vol. 34, no. 9, pp. 1977-1983, 2012.

[32] N. L. Zaharan, D. Williams, and K. Bennett, "Statins and risk of treated incident diabetes in a primary care population,"
British Journal of Clinical Pharmacology, vol. 75, no. 4, pp. 1118-1124, 2013.

[33] T. Takano, T. Yamakawa, M. Takahashi, M. Kimura, and A. Okamura, "Influences of statins on glucose tolerance in patients with type 2 diabetes mellitus," Journal of Atherosclerosis and Thrombosis, vol. 13, no. 2, pp. 95-100, 2006.

[34] H. Cederberg, A. Stančáková, N. Yaluri, S. Modi, J. Kuusisto, and M. Laakso, "Increased risk of diabetes with statin treatment is associated with impaired insulin sensitivity and insulin secretion: a 6 year follow-up study of the METSIM cohort," Diabetologia, vol. 58, no. 5, pp. 1109-1117, 2015.

[35] Y. Cho, E. Choe, Y. H. Lee et al., "Risk of diabetes in patients treated with HMG-CoA reductase inhibitors," Metabolism, vol. 64, no. 4, pp. 482-488, 2015.

[36] J. Y. Park, S. W. Rha, B. Choi et al., "Impact of low dose atorvastatin on development of new-onset diabetes mellitus in Asian population: three-year clinical outcomes," International Journal of Cardiology, vol. 184, pp. 502-506, 2015.

[37] C. W. Chen, T. C. Chen, K. Y. Huang, P. Chou, P. F. Chen, and C. C. Lee, "Differential impact of statin on new-onset diabetes in different age groups: a population-based case-control study in women from an asian country," PLoS One, vol. 8, no. 8, article e71817, 2013.

[38] P. Amarenco, J. Bogousslavsky, A. Callahan 3rd et al., "Highdose atorvastatin after stroke or transient ischemic attack," The New England Journal of Medicine, vol. 355, no. 6, pp. 549-559, 2006.

[39] P. M. Ridker, A. Pradhan, J. G. MacFadyen, P. Libby, and R. J. Glynn, "Cardiovascular benefits and diabetes risks of statin therapy in primary prevention: an analysis from the JUPITER trial," Lancet, vol. 380, no. 9841, pp. 565-571, 2012.

[40] B. Chogtu, R. Magazine, and K. L. Bairy, "Statin use and risk of diabetes mellitus," World Journal of Diabetes, vol. 6, no. 2, pp. 352-357, 2015.

[41] H. Naci, J. Brugts, and T. Ades, "Comparative tolerability and harms of individual statins: a study-level network metaanalysis of 246955 participants from 135 randomized, controlled trials," Circulation. Cardiovascular Quality and Outcomes, vol. 6, no. 4, pp. 390-399, 2013.

[42] D. Preiss, S. R. Seshasai, P. Welsh et al., "Risk of incident diabetes with intensive-dose compared with moderate-dose statin therapy: a meta-analysis," JAMA, vol. 305 , no. 24 , pp. $2556-$ 2564, 2011.

[43] B. Zafrir and M. Jain, "Lipid-lowering therapies, glucose control and incident diabetes: evidence, mechanisms and clinical implications," Cardiovascular Drugs and Therapy, vol. 28, no. 4, pp. 361-377, 2014.

[44] M. Laakso and J. Kuusisto, "Diabetes secondary to treatment with statins," Current Diabetes Reports, vol. 17, no. 2, p. 10, 2017.

[45] K. K. Koh, I. Sakuma, and M. J. Quon, "Differential metabolic effects of distinct statins," Atherosclerosis, vol. 215, no. 1, pp. 18, 2011.

[46] A. J. Rahal, A. I. ElMallah, R. J. Poushuju, and R. Itani, “Do statins really cause diabetes? A meta-analysis of major randomized controlled clinical trials," Saudi Medical Journal, vol. 37, no. 10, pp. 1051-1060, 2016.

[47] D. Thakker, S. Nair, A. Pagada, V. Jamdade, and A. Malik, "Statin use and the risk of developing diabetes: a network meta-analysis," Pharmacoepidemiology and Drug Safety, vol. 25, no. 10, pp. 1131-1149, 2016. 
[48] E. P. Navarese, A. Buffon, F. Andreotti et al., "Meta-analysis of impact of different types and doses of statins on new-onset diabetes mellitus," The American Journal of Cardiology, vol. 111, no. 8, pp. 1123-1130, 2013.

[49] K. Ray, "Statin diabetogenicity: guidance for clinicians," Cardiovascular Diabetology, vol. 12, Supplement 1, p. S3, 2013.

[50] Y. Zhou, Y. Yuan, R. R. Cai et al., "Statin therapy on glycaemic control in type 2 diabetes: a meta-analysis," Expert Opinion on Pharmacotherapy, vol. 14, no. 12, pp. 1575-1584, 2013.

[51] J. Sasaki, M. Iwashita, and S. Kono, "Statins: beneficial or adverse for glucose metabolism," Journal of Atherosclerosis and Thrombosis, vol. 13, no. 3, pp. 123-129, 2006.

[52] M. Nakata, S. Nagasaka, I. Kusaka, H. Matsuoka, S. Ishibashi, and T. Yada, "Effects of statins on the adipocyte maturation and expression of glucose transporter 4 (SLC2A4): implications in glycaemic control," Diabetologia, vol. 49, no. 8, pp. 1881-1892, 2006.

[53] T. Yada, M. Nakata, T. Shiraishi, and M. Kakei, "Inhibition by simvastatin, but not pravastatin, of glucose-induced cytosolic $\mathrm{Ca} 2+$ signalling and insulin secretion due to blockade of $\mathrm{L}$ type Ca2+ channels in rat islet beta-cells," British Journal of Pharmacology, vol. 126, no. 5, pp. 1205-1213, 1999.

[54] H. Mabuchi, T. Higashikata, M. Kawashiri et al., "Reduction of serum ubiquinol-10 and ubiquinone-10 levels by atorvastatin in hypercholesterolemic patients," Journal of Atherosclerosis and Thrombosis, vol. 12, no. 2, pp. 111-119, 2005.

[55] M. Ishikawa, A. Namiki, T. Kubota et al., "Effect of pravastatin and atorvastatin on glucose metabolism in nondiabetic patients with hypercholesterolemia," Internal Medicine, vol. 45, no. 2, pp. 51-55, 2006.

[56] G. Rena, D. G. Hardie, and E. R. Pearson, "The mechanisms of action of metformin," Diabetologia, vol. 60, no. 9, pp. 15771585, 2017.

[57] J. Jin, H. Zeng, O. Yang, and J. Kong, “The endothelial protective effects of pioglitazone on insulin resistance in endothelial cells," Clinical Laboratory, vol. 60, no. 7, pp. 1129-1134, 2014.

[58] U. Smith, "Pioglitazone: mechanism of action," International Journal of Clinical Practice, vol. 121, pp. 13-18, 2001.

[59] T. Kimura, H. Kaneto, M. Shimoda et al., "Protective effects of pioglitazone and/or liraglutide on pancreatic $\beta$-cells in $\mathrm{db} / \mathrm{db}$ mice: comparison of their effects between in an early and advanced stage of diabetes," Molecular and Cellular Endocrinology, vol. 400, pp. 78-89, 2015.

[60] D. Sola, L. Rossi, G. P. C. Schianca et al., "Sulfonylureas and their use in clinical practice," Archives of Medical Science, vol. 11, no. 4, pp. 840-848, 2015.

[61] K. Khunti, S. Chatterjee, H. C. Gerstein, S. Zoungas, and M. J. Davies, "Do sulphonylureas still have a place in clinical practice?," The Lancet Diabetes and Endocrinology, vol. 6, no. 10, pp. 821-832, 2018.

[62] D. J. Drucker, "Mechanisms of action and therapeutic application of glucagon-like peptide-1," Cell Metabolism, vol. 27, no. 4, pp. 740-756, 2018.

[63] E. E. Mulvihill and D. J. Drucker, "Pharmacology, physiology, and mechanisms of action of dipeptidyl peptidase- 4 inhibitors," Endocrine Reviews, vol. 35, no. 6, pp. 992-1019, 2014.

[64] S. Kalra, "Glucagon-like peptide-1 receptors agonists (GLP1 RA)," The Journal of the Pakistan Medical Association, vol. 63, no. 10, pp. 1312-1315, 2013.

[65] K. I. Cho, I. Sakuma, I. S. Sohn, T. Hayashi, K. Shimada, and K. K. Koh, "Best treatment strategies with statins to maximize the cardiometabolic benefits," Circulation Journal, vol. 82, no. 4, pp. 937-943, 2018.

[66] P. C. Underwood and G. K. Adler, "The renin angiotensin aldosterone system and insulin resistance in humans," Current Hypertension Reports, vol. 15, no. 1, pp. 59-70, 2013.

[67] F. Andreozzi, E. Laratta, A. Sciacqua, F. Perticone, and G. SestiAngiotensin II impairs the insulin signaling pathway promoting production of nitric oxide by inducing phosphorylation of insulin receptor substrate-1 on Ser312 and Ser616 in human umbilical vein endothelial cells," Circulation Research, vol. 94, no. 9, pp. 1211-1218, 2004.

[68] Y. Izawa, M. Yoshizumi, Y. Fujita et al., "ERK1/2 activation by angiotensin II inhibits insulin-induced glucose uptake in vascular smooth muscle cells," Experimental Cell Research, vol. 308, no. 2, pp. 291-299, 2005.

[69] C. Tikellis, P. J. Wookey, R. Candido, S. Andrikopoulos, M. C. Thomas, and M. E. Cooper, "Improved islet morphology after blockade of the renin-angiotensin system in the ZDF rat," Diabetes, vol. 53, no. 4, pp. 989-997, 2004.

[70] G. C. Weir, C. Aguayo-Mazzucato, and S. Bonner-Weir, “ $\beta$ cell dedifferentiation in diabetes is important, but what is it?," Islets, vol. 5, no. 5, pp. 233-237, 2013.

[71] H. Chen, W. Zhou, Y. Ruan et al., "Reversal of angiotensin llinduced $\beta$-cell dedifferentiation via inhibition of NF- $\kappa b$ signaling," Molecular Medicine, vol. 24, no. 1, p. 43, 2018.

[72] H. Takagi and T. Umemoto, "Telmisartan improves insulin sensitivity: a meta-analysis of randomized head-to-head trials," International Journal of Cardiology, vol. 156, no. 1, pp. 92-96, 2012.

[73] G. Paolisso, M. R. Tagliamonte, A. Gambardella et al., "Losartan mediated improvement in insulin action is mainly due to an increase in non-oxidative glucose metabolism and blood flow in insulin-resistant hypertensive patients," Journal of Human Hypertension, vol. 11, no. 5, pp. 307-312, 1997.

[74] A. Moan, A. Høieggen, G. Nordby, I. K. Eide, and S. E. Kjeldsen, "Effects of losartan on insulin sensitivity in severe hypertension: connections through sympathetic nervous system activity?," Journal of Human Hypertension, vol. 9, Supplement 5, pp. S45-S50, 1995.

[75] K. Suzuki, O. Nakagawa, and Y. Aizawa, "Improved earlyphase insulin response after candesartan treatment in hypertensive patients with impaired glucose tolerance," Clinical and Experimental Hypertension, vol. 30, no. 5, pp. 309-314, 2008.

[76] T. S. Perlstein, R. R. Henry, K. J. Mather et al., "Effect of angiotensin receptor blockade on insulin sensitivity and endothelial function in abdominally obese hypertensive patients with impaired fasting glucose," Clinical Science, vol. 122, no. 4, pp. 193-202, 2012.

[77] S. H. Ko, H. S. Kwon, S. R. Kim et al., "Ramipril treatment suppresses islet fibrosis in Otsuka Long-Evans Tokushima fatty rats," Biochemical and Biophysical Research Communications, vol. 316, no. 1, pp. 114-122, 2004.

[78] T. Shiuchi, T. X. Cui, L. Wu et al., "ACE inhibitor improves insulin resistance in diabetic mouse via bradykinin and NO," Hypertension, vol. 40, no. 3, pp. 329-334, 2002.

[79] B. Singh, A. Mourya, S. P. Sah, and A. Kumar, "Protective effect of losartan and ramipril against stress induced insulin resistance and related complications: anti-inflammatory mechanisms," European Journal of Pharmacology, vol. 801, pp. 54-61, 2017. 
[80] R. S. Weisinger, T. K. Stanley, D. P. Begg, H. S. Weisinger, K. J. Spark, and M. Jois, "Angiotensin converting enzyme inhibition lowers body weight and improves glucose tolerance in C57BL/ 6J mice maintained on a high fat diet," Physiology \& Behavior, vol. 98, no. 1-2, pp. 192-197, 2009.

[81] U. N. Das, "Renin-angiotensin-aldosterone system in insulin resistance and metabolic syndrome," Journal of Translational Internal Medicine, vol. 4, no. 2, pp. 66-72, 2016.

[82] K. Putnam, R. Shoemaker, F. Yiannikouris, and L. A. Cassis, "The renin-angiotensin system: a target of and contributor to dyslipidemias, altered glucose homeostasis, and hypertension of the metabolic syndrome," American Journal of Physiology. Heart and Circulatory Physiology, vol. 302, no. 6, pp. H1219H1230, 2012.

[83] Ç. Bitkin Eda, B. Mehmet, T. Necati et al., "Effects of ACE inhibitors on insulin resistance and lipid profile in children with metabolic syndrome," Journal of Clinical Research in Pediatric Endocrinology, vol. 5, no. 3, pp. 164-169, 2013.

[84] E. L. Gillespie, C. M. White, M. Kardas, M. Lindberg, and C. I. Coleman, "The impact of ACE inhibitors or angiotensin II type 1 receptor blockers on the development of newonset type 2 diabetes," Diabetes Care, vol. 28, no. 9, pp. 2261-2266, 2005.

[85] J. J. McMurray, R. R. Holman, S. M. Haffner et al., "Effect of valsartan on the incidence of diabetes and cardiovascular events," The New England Journal of Medicine, vol. 362, no. 16, pp. 1477-1490, 2010.

[86] L. V. Solski and D. S. Longyhore, "Prevention of type 2 diabetes mellitus with angiotensin-converting-enzyme inhibitors," American Journal of Health-System Pharmacy, vol. 65, no. 10, pp. 935-940, 2008.

[87] H. Abuissa, P. G. Jones, S. P. Marso, and J. H. O’Keefe Jr, "Angiotensin-converting enzyme inhibitors or angiotensin receptor blockers for prevention of type 2 diabetes: a metaanalysis of randomized clinical trials," Journal of the American College of Cardiology, vol. 46, no. 5, pp. 821-826, 2005.

[88] L. M. Prisant, "Preventing type II diabetes mellitus," Journal of Clinical Pharmacology, vol. 44, no. 4, pp. 406-413, 2004.

[89] M. M. Haluzík and M. Haluzík, "PPAR-alpha and insulin sensitivity," Physiological Research, vol. 55, no. 2, pp. 115-122, 2006.

[90] T. Damci, S. Tatliagac, Z. Osar, and H. Ilkova, "Fenofibrate treatment is associated with better glycemic control and lower serum leptin and insulin levels in type 2 diabetic patients with hypertriglyceridemia," European Journal of Internal Medicine, vol. 14, no. 6, pp. 357-360, 2003.

[91] S. M. H. Chan, R. Q. Sun, X. Y. Zeng et al., "Activation of PPAR $\alpha$ ameliorates hepatic insulin resistance and steatosis in high fructose-fed mice despite increased endoplasmic reticulum stress," Diabetes, vol. 62, no. 6, pp. 2095-2105, 2013.

[92] R. Elkeles, "Fibrates: old drugs with a new role in type 2 diabetes prevention?," The British Journal of Diabetes \& Vascular Disease, vol. 11, no. 1, pp. 4-9, 2011.

[93] M. J. Graham, R. G. Lee, T. A. Brandt et al., "Cardiovascular and metabolic effects of ANGPTL3 antisense oligonucleotides," The New England Journal of Medicine, vol. 377, no. 3, pp. 222-232, 2017.
[94] M. S. Kostapanos, G. L. Liamis, H. J. Milionis, and M. S. Elisaf, "Do statins beneficially or adversely affect glucose homeostasis?," Current Vascular Pharmacology, vol. 999, no. 999, pp. 1-20, 2010.

[95] T. R. Pedersen, O. Faergeman, J. J. Kastelein et al., "High-dose atorvastatin vs usual-dose simvastatin for secondary prevention after myocardial infarction: the ideal study: a randomized controlled trial-correction," JAMA, vol. 294, no. 19, pp. $2437-$ 2445, 2005. 


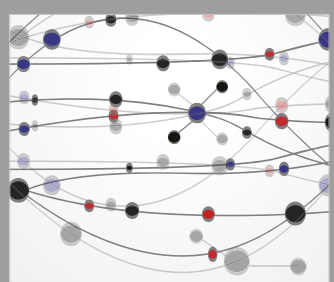

The Scientific World Journal
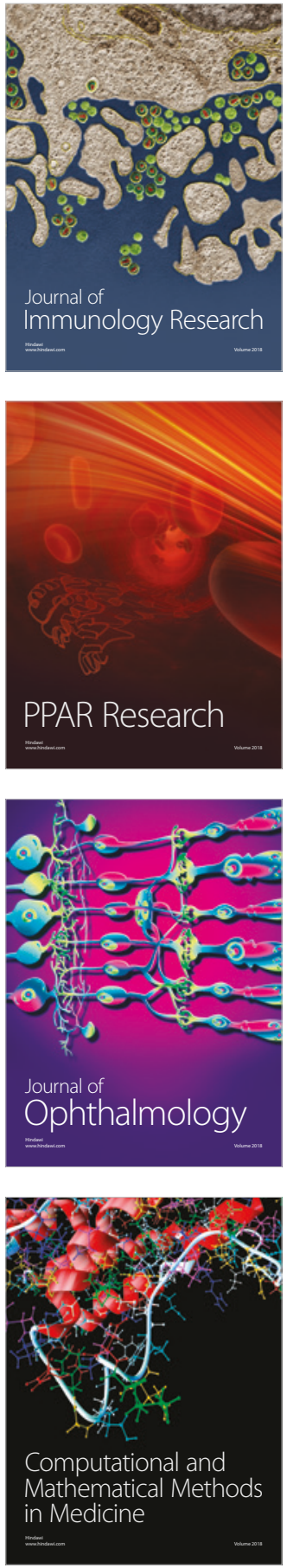

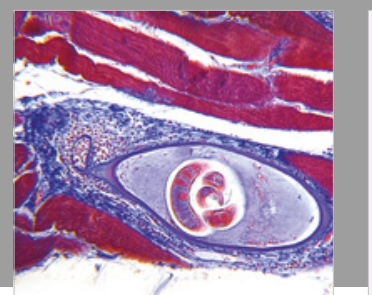

Gastroenterology Research and Practice

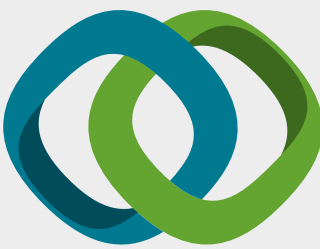

\section{Hindawi}

Submit your manuscripts at

www.hindawi.com
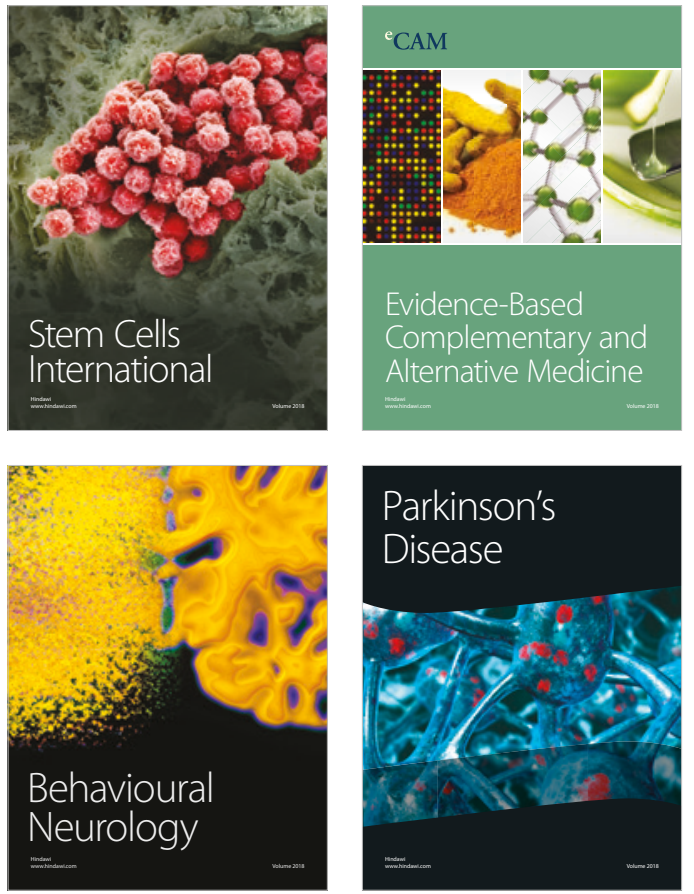

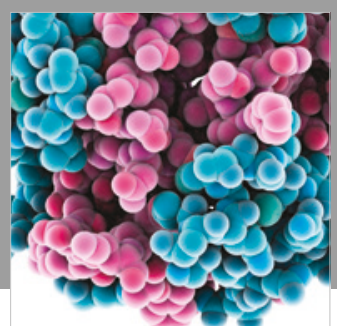

ournal of

Diabetes Research

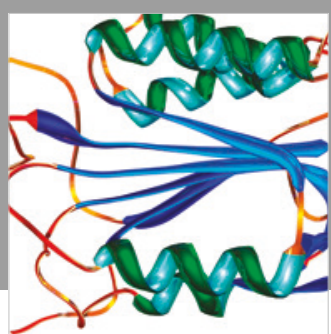

Disease Markers
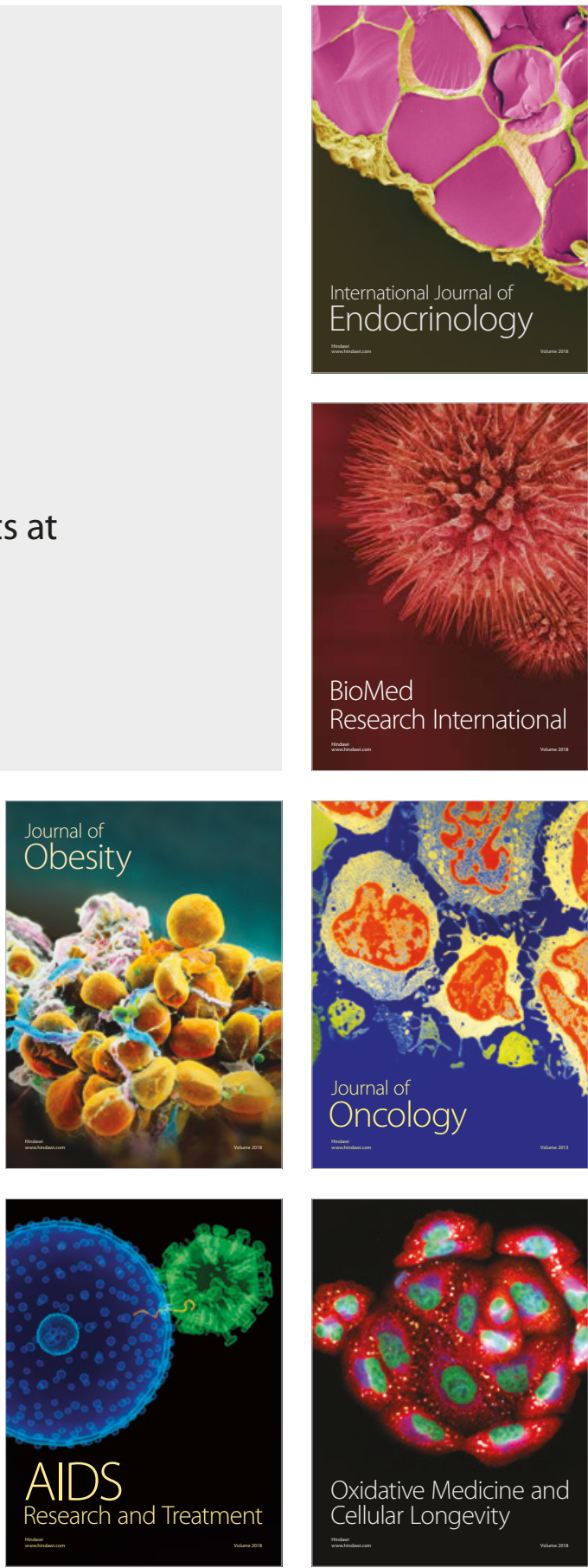